\title{
SHIPPING EMISSIONS AND THEIR IMPACT ON AIR QUALITY IN URBAN COASTAL AREAS: PRESENT AND FUTURE SCENARIOS
}

\author{
ALEXANDRA MONTEIRO, MICHAEL RUSSO, CARLA GAMA \& CARLOS BORREGO \\ CESAM \& Department of Environment and Planning, University of Aveiro, Portugal
}

\begin{abstract}
Due to its dependence on fossil fuel combustion, emissions from the marine transport sector can significantly contribute to air pollution, particularly over coastal areas where most people live. The AIRSHIP research project (http://airship.web.ua.pt/) aims to evaluate this contribution and how it affects air quality, with Portugal as case study and using a numerical air quality modelling approach with high-resolution emission data. Shipping emissions from the STEAM project inventory were compiled and pre-processed at an hourly and high spatial resolution, regarding current (2015) scenario and future (2030-2050) projections. Scenarios with and without the maritime emissions were then simulated with the WRF-CHIMERE modelling system, amply tested and validated over Europe and Portugal, in order to evaluate its impact on air quality for both present and future scenarios. This modelling system was applied first for Europe $\left(27 \times 27 \mathrm{~km}^{2}\right)$ and then to the Portugal domain using a nesting approach with a sufficient spatial high-resolution $\left(3 \times 3 \mathrm{~km}^{2}\right)$ to allow the estimation of the impact over urban coastal areas. The talk will present part of the results of the AIRSHIP research project, finishing in July 2019, namely regarding the comparison of the modelling results (with and without considering maritime emissions), for both present and future scenarios, with focus over the main urban coastal areas of Portugal and considering the main atmospheric pollutants $-\mathrm{NO}_{2}, \mathrm{PM}, \mathrm{SO}_{2}$ and $\mathrm{O}_{3}$. Preliminary results highlight the major urban areas affected by shipping transport - Porto, Lisbon and south of Lisbon - for both present and future scenarios. For present conditions, maritime emissions are responsible for $10 \%-20 \%$ of the PM and NOx mass concentrations over those urban areas. Regarding future projections, a reduction of this impact is expected (4-5\%), mainly in terms of $\mathrm{NO}_{2}$ and PM10 pollutants.

Keywords: shipping emissions, future projections, modelling, air quality.
\end{abstract}

\section{INTRODUCTION}

Due to high pollutant emissions, intensive energy consumption and a complex economic system, the transportation sector has been a focus of the scientific community [1]-[4]. International shipping has been a fast-growing sector of the global economy and its share of total anthropogenic emissions is significant, having effects on climate, air quality, and human health. Projections indicate that shipping emissions will surpass all land emission sources of SOx and NOx, for the Europe domain in the coming years, if not properly studied and sustainably regulated [5].

The European Commission and maritime industry have a long-term objective of "zero-waste, zero-emission" for maritime transport [6]. This is being put into practice with a joint effort from the European Union and the International Maritime Organization (IMO). The objective is to reduce greenhouse gas emissions, mainly for international shipping, and manage the amendment of the IMO to reduce sulphur oxides and nitrogen oxides emissions from ships.

This study is focused on the impacts of shipping emissions on regional air quality in particular over the coastal area of Portugal, which has a large amount of ship traffic along the western and southern coast. For the present scenario the base year of 2015 was considered, since it corresponds with the most recent year with available input data, namely meteorology 
and shipping emissions. For the future scenario, both changes in climate and shipping emissions were included: the RCP8.5 climate change scenario (year 2050) and emission projections for shipping from STEAM model were considered.

The paper is structured as followed: section 2 describes the modelling setup methodology, including a brief description of the case study. The main results are presented in Section 3 , including the analysis of shipping emissions and air quality modelling results. Conclusions follow in Section 4.

\section{METHODOLOGY}

The study was performed by applying a numerical modelling system comprised of the WRF weather forecast model and the CHIMERE chemistry-transport model. This modelling system has already been widely used and validated for these types of studies [7]. WRF runs were made for 2015 (present scenario) and 2050 (RCP 8.5 future scenario). An emissions inventory was built using the updated $0.1^{\circ} \mathrm{x} 0.1^{\circ}$ emissions inventory, from the EMEP Centre on Emission Inventories and Projections (CEIP), combined with data from the STEAM shipping emissions model [8]-[11].

Fig. 1 exemplified the structure of the numerical modelling system used with the respective input and output data.

The simulations were performed for different domains using a nesting approach in order to obtain a high-detailed simulation over the finest domain over Portugal, starting with a coarse domain of $27 \times 27 \mathrm{~km}^{2}$ over Europe and North Africa, then $9 \times 9 \mathrm{~km}^{2}$ over the Iberian Peninsula and finally a $3 \times 3 \mathrm{~km}^{2}$ domain over Portugal.

Fig. 2 shows the domains used and described above (ArcGis software).

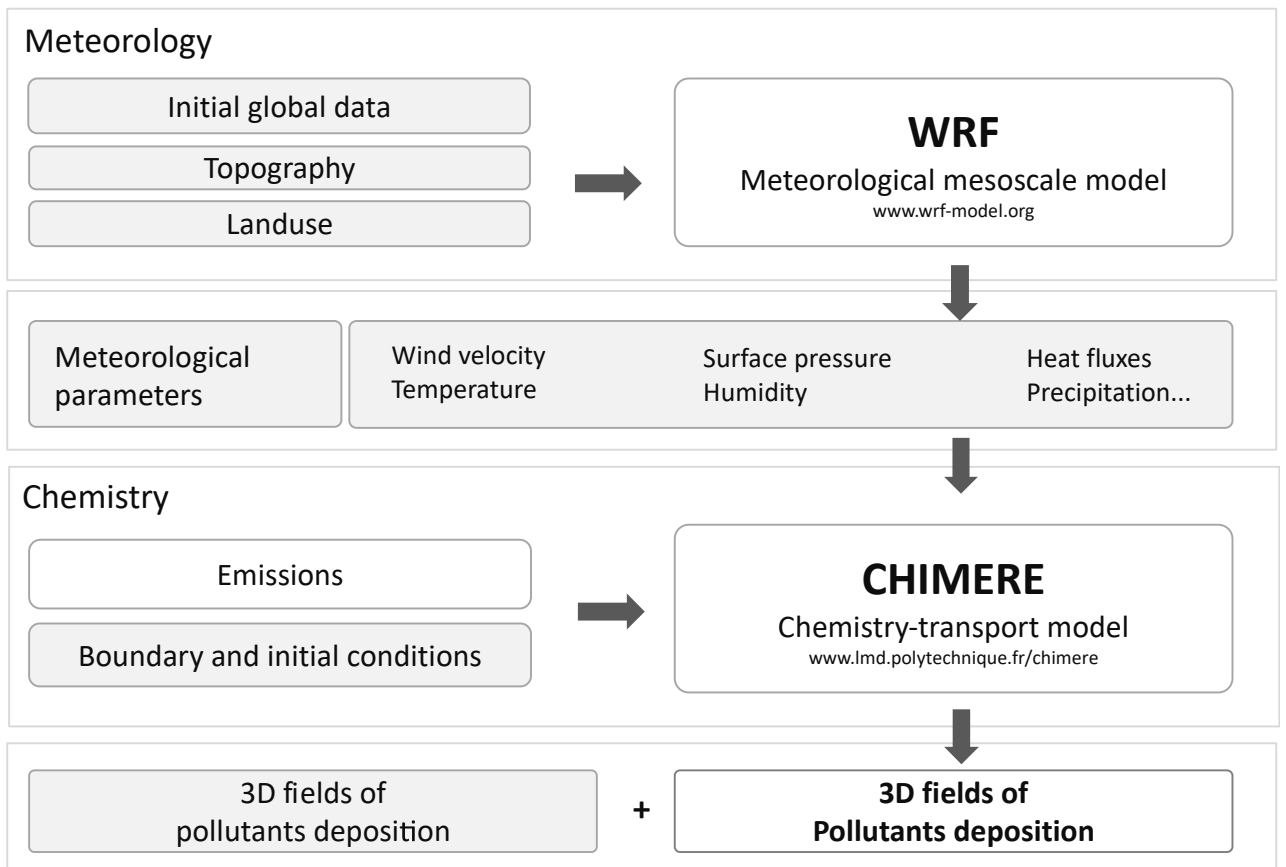

Figure 1: Air quality modelling system used for the air quality impact assessment. 


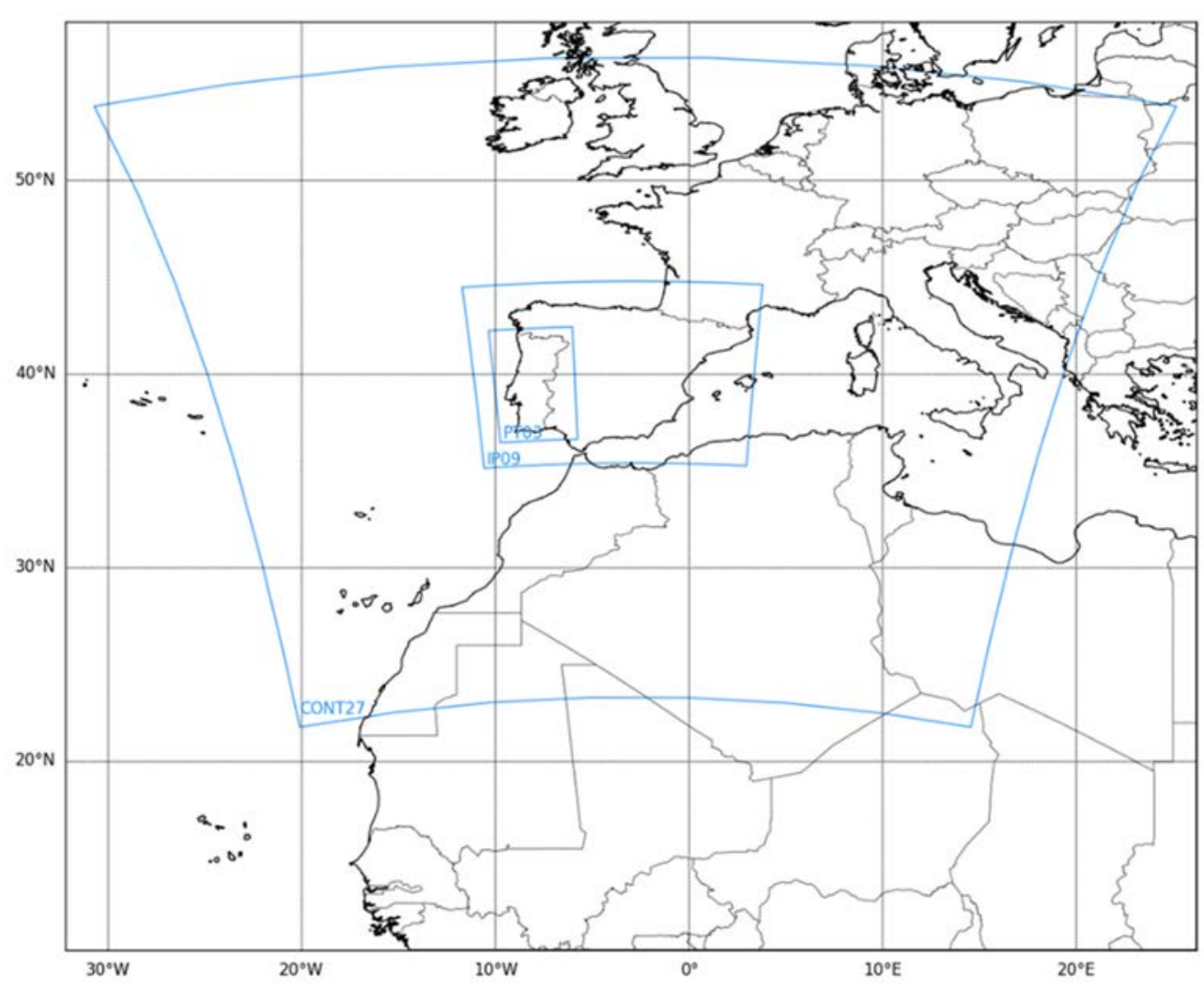

Figure 2: Simulation domains used in the model application.

\section{RESULTS AND DISCUSSION}

First, it is presented - Fig. 3 - the emission data calculated by the STEAM model for the Europe domain, for both present (2015) and future (2050) scenarios, and for the main atmospheric pollutants.

For all the pollutants, without exceptions, reductions are predicted in future projections, which is verified over the main international routes as well as in the secondary ones. The maps also indicate that the major reductions are expected also for $\mathrm{SO}_{2}$, a pollutant that have been focus of large regulation in the last years.

In terms of spatial distribution, we can identify that the Baltic Sea will be the area where more reductions in terms of shipping emissions are expected, which is explain by the specific and restrict regulations that were developed and implemented for this particular area - the so-called SECA area (Sulfur Emission Control Areas), effective after 2015, with the maximum permissible sulphur content of marine fuels limited from the current value of $1.0 \%$ to only $0.1 \%$. Over the Mediterranean area, the other hotspot in terms of shipping emissions, it is not expected these limitations and consequent reductions.

In order to analyse the differences found between the different simulations (for both present and future conditions), the maximum hourly deltas were calculated, and for the main pollutants: $\mathrm{NOx}, \mathrm{SO}_{2}, \mathrm{PM} 2.5$ and $\mathrm{O}_{3}$, as shown in Fig. 4. Only the Portugal domain is 

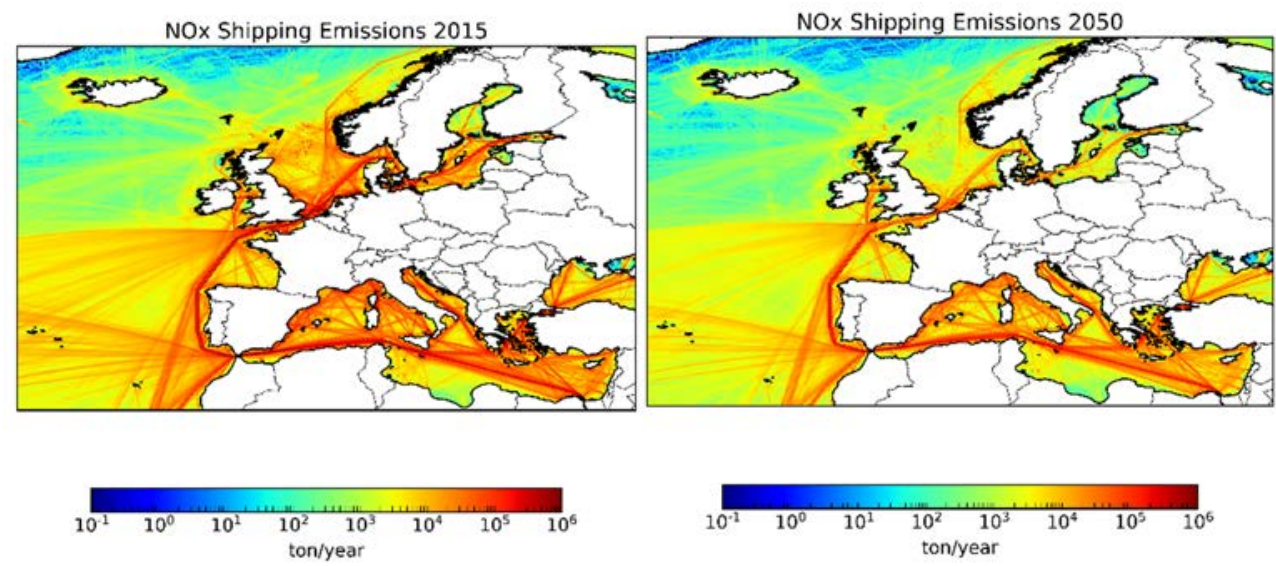

PM25 Shipping Emissions 2015

PM25 Shipping Emissions 2050

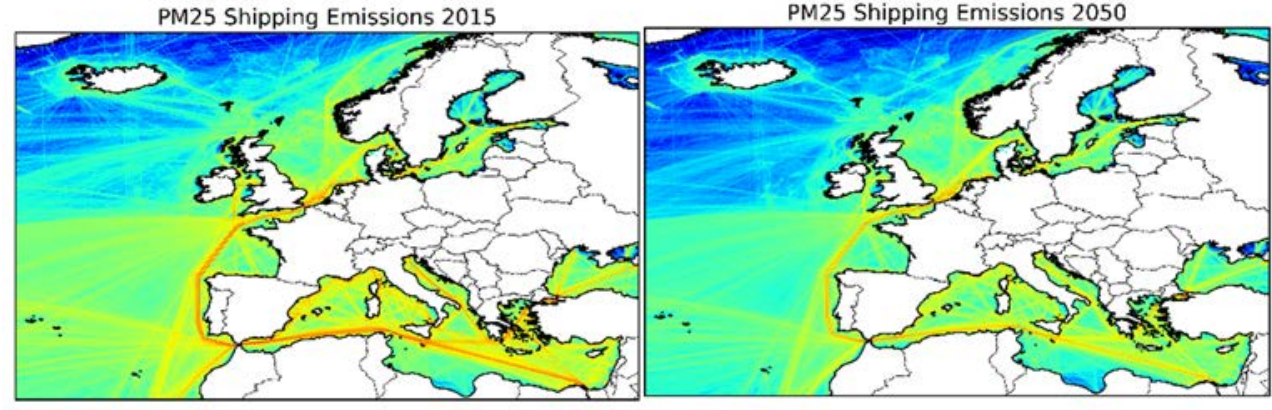

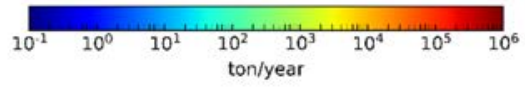
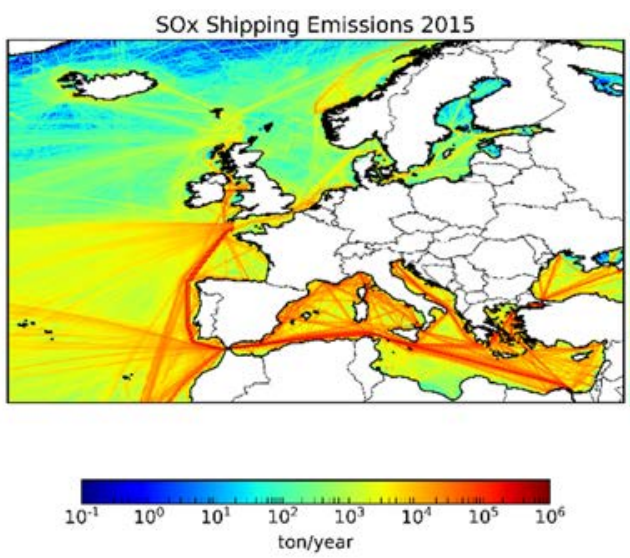

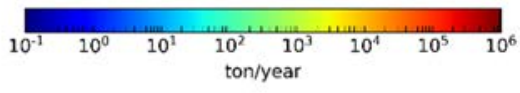

SOx Shipping Emissions 2050
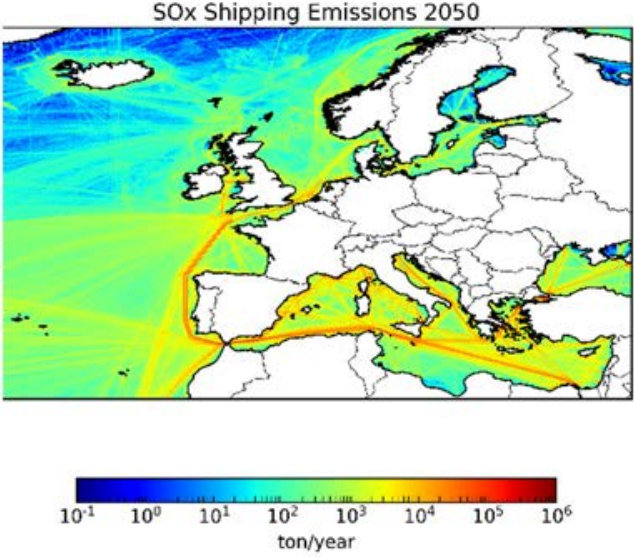

Figure 3: Emissions from shipping for NOx, PM2.5 and SOx (in ton/year) over the European domain, for present (2015) and future (2050) scenarios. 

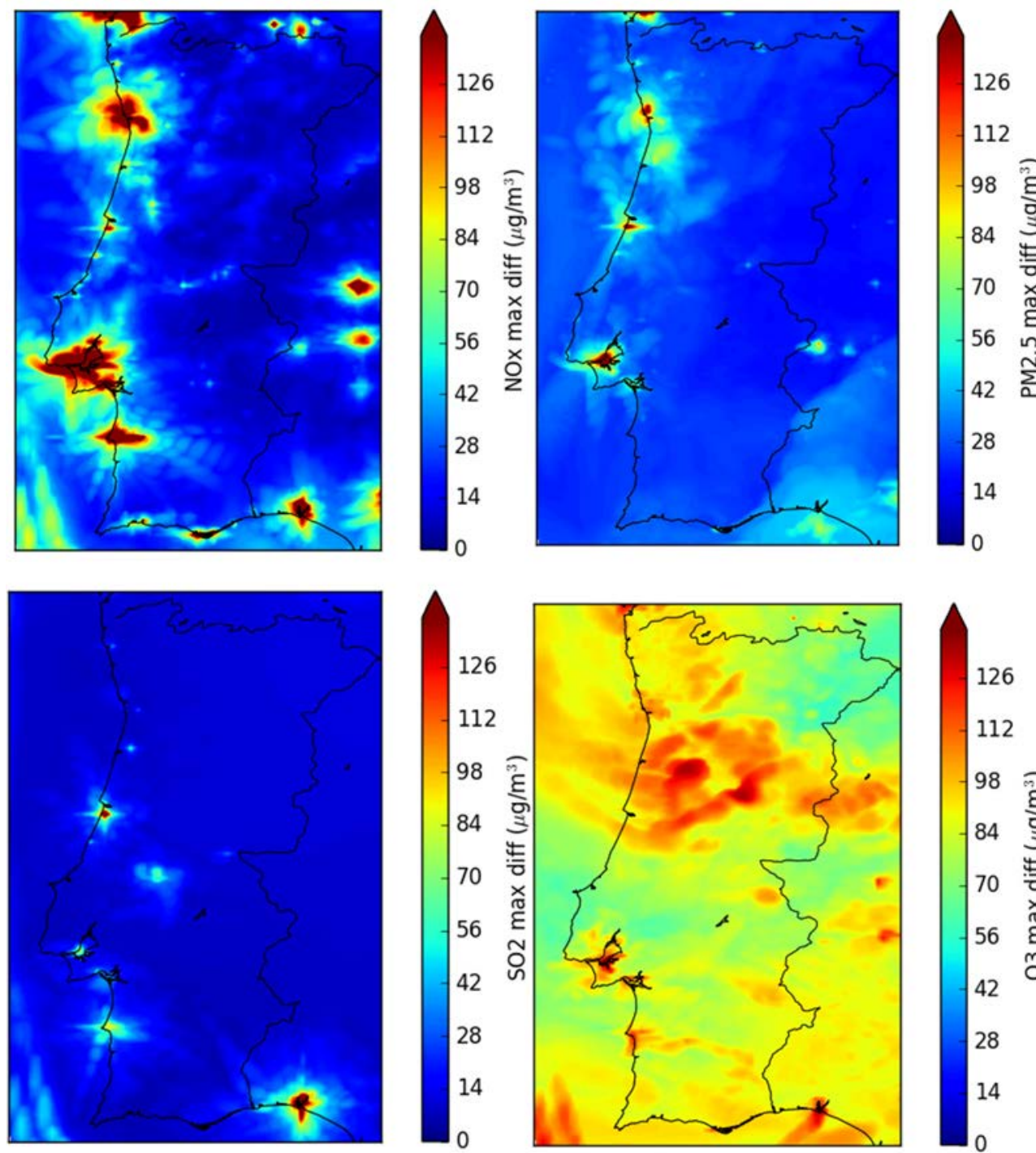

Figure 4: Maximum differences found between the present (2015) and future (2050) case scenarios for the main critical pollutants - NOx, $\mathrm{SO}_{2}, \mathrm{PM} 2.5$ and $\mathrm{O}_{3}$ - focusing on Portugal domain.

presented, according to the main objective of studying the impact of shipping in future conditions over the coastal and urbanized area of Portugal.

Besides the reduction expected for the shipping emissions, the air quality modelling results suggest an increase of pollutants concentration in future scenario, in particular over the coast and urbanized areas of Portugal.

This indicates that besides the overall trend on emission reduction, the climate forcing expected for the RCP8.5 scenario will be responsible for significant changes in pollutants 
concentrations, in particular over urban and coastal areas. The differences in ozone are visible in a significantly larger area, also having a large impact in inland locations, which is explained by the secondary origin of $\mathrm{O}_{3}$, associated to the transport and dispersion of its precursors. The maximum differences for $\mathrm{O}_{3}$ in inland locations register up to $80 \mathrm{ug} \cdot \mathrm{m}^{-3}$.

Additional simulations are foreseen to evaluate the contribution of each forcing (emissions and climate) and better understand the role of each component.

\section{CONCLUSIONS}

A numerical modelling approach, based on the WRF-CHIMERE modelling system, was used to evaluate the impact of shipping on the air quality for present (2015 base year) and future scenarios (2050 year 5). The study focused on the Portugal domain, and more particular over the urbanized coast of Portugal, due to the large amount of shipping emissions in international routes around the region, considering the most critical pollutants for the area $\left(\mathrm{NOx}, \mathrm{SO}_{2}, \mathrm{PM}\right.$ and $\mathrm{O}_{3}$ ). A high-resolution inventory for shipping emissions was used for present and future projections of shipping emissions (STEAM) and the RCP8 IPCC climate scenario was adopted for future climate scenario (considering the worst case - but also the most probable - situation in terms of climate changing).

Regarding the shipping emissions projection, reductions are expected for all the pollutants $-\mathrm{NOx}, \mathrm{SO}_{2}$ and $\mathrm{PM}$ - with major reductions over the Baltic Sea (one of the hotpots in Europe in terms of shipping emissions).

The air quality modelling results show an increase of all the main critical pollutants, in terms of maximum values expected, mainly at urban areas, with deltas up to $100 \mathrm{ug} . \mathrm{m}^{-3}$ for NOx or 70 ug. $\mathrm{m}^{-3}$ for PM2.5. Since shipping emissions are going to decrease in the future, these deltas are due to the effect/impact of climate change.

These results are particularly important in understanding and quantifying the future impact of both shipping emissions and climate change to regional air quality. Future work will include more additional simulations to evaluate the contribution of emissions and climate forcing separately, and a detailed analysis of the seasonality of pollutant concentrations, as well as building guidelines for the maritime sector according to these findings, aiding decision-makers in understanding how shipping can have a more sustainable growth.

\section{ACKNOWLEDGEMENTS}

The authors acknowledge the support of AIRSHIP project (PTDC/AAG-MAA/1581/2014; POCI-01-0145-FEDER-016708), funded by the Portuguese Science and Technology Foundation through national funds and by the European Community Fund FEDER within the COMPETE2020 program.

Thanks are due for the financial support to CESAM (UID/AMB/50017/2019), to FCT/MCTES through national funds, and the co-funding by the FEDER, within the PT2020 Partnership Agreement and Compete 2020.

\section{REFERENCES}

[1] Brandt, J. et al., Assessment of past, present and future health-cost externalities of air pollution in Europe and the contribution from international ship traffic using the EVA model system. Atmospheric Chemistry and Physics, 13(15), pp. 7747-7764, 2013.

[2] Ballini, F. \& Bozzo, R., Air pollution from ships in ports: The socio-economic benefit of cold-ironing technology. Research in Transportation Business \& Management, 17, pp. 92-98, 2015. 
[3] Liu, H. et al., The impact of marine shipping and its DECA control on air quality in the Pearl River Delta, China. Science of the Total Environment, 625, pp. 1476-1485, 2018.

[4] Sofiev, M. et al., Cleaner fuels for ships provide public health benefits with climate tradeoffs. Nature Communications, 9(1), pp. 406, 2018

[5] European Environment Agency (EEA), Technical report No 4/2013. The impact of international shipping on European air quality and climate forcing, 2013.

[6] Commission of the European Communities (CEC), Strategic goals and recommendations for the EU's maritime transport policy until 2018, 2009.

[7] Monteiro, A, Russo, M., Gama, C. \& Borrego, C., How important are maritime emissions for the air quality: At European and national scale. Environmental Pollution, 242, pp. 565-575, 2018.

[8] Jalkanen, J.-P., Brink, A., Kalli, J., Pettersson, H., Kukkonen, J. \& Stipa, T., A modelling system for the exhaust emissions of marine traffic and its application in the Baltic Sea area. Atmospheric Chemistry and Physics, 9(23), pp. 9209-9223, 2009.

[9] Jalkanen, J.-P., Johansson, L., Brink, A., Kalli, J., Kukkonen, J. \& Stipa, T., Extension of an assessment model of ship traffic exhaust emissions for particulate matter and carbon monoxide. Atmospheric Chemistry and Physics, 12(5), pp. 2641-2659, 2012.

[10] Johansson, L., Jalkanen, J.-P. \& Kukkonen, J., Global assessment of shipping emissions in 2015 on a high spatial and temporal resolution. Atmospheric Environment, 167, pp. 403-415, 2017.

[11] Johansson, L., Jalkanen, J.-P., Kalli, J. \& Kukkonen, J., The evolution of shipping emissions and the costs of recent and forthcoming emission regulations in the northern European emission control area. Atmospheric Chemistry and Physics, 13(6), pp. 11375-11389, 2013. 